DOI 10.1590/S0104-64972015002325

\title{
Reproductive aspects of Hyalella carstica (Amphipoda: Hyalellidae) in a natural environment in southeastern Brazil
}

Silvia Helena Soares Torres, Rafaela Bastos-Pereira and Alessandra Angélica de Pádua Bueno

(SHST, RB-P, AAPB) Programa de Pós-Graduação em Ecologia Aplicada, Departamento de Biologia, Universidade Federal de Lavras. 37200-000 Lavras, Minas Gerais, Brazil. E-mail: (AAPB) aapbueno@ yahoo.com.br

\begin{abstract}
The reproductive aspects of populations are important determinants of their ability to maintain themselves throughout time. In the case of amphipods from the genus Hyalella Smith, 1874, the reproductive period is easily determined by the presence of ovigerous females and pre-copula pairs in the population. This study evaluated the fecundity, pairing patterns and reproduction period of Hyalella carstica Bastos-Pereira and Bueno, 2012 in a karst environment in the West of Minas Gerais, Brazil. Monthly, from April, 2010 to April, 2011, amphipods were sampled using a hand net with $15 \mathrm{~cm}$ diameter and $250 \mu \mathrm{m}$ mesh size. In the laboratory, animals were sexed and measured, and the ovigerous state of females was evaluated. Couples in pre-copula and ovigerous females were found throughout the year, with the exception of the dry months (September-November). During drought, the stream's superficial water dried out, and only a few refuges for the population remained. Although couples were found in all months with a water flow, a higher number of unpaired males and females was found after the dry season. In all months, ovigerous females were more abundant than non-ovigerous, and the relationship between head length and the number of eggs in the marsupium was positive. Most eggs were in the first developmental stage, although all other stages were found before the dry season. Considering the frequency of pre-copula pairs, as well as ovigerous females, the reproduction in this $H$. carstica population seems to be continuous throughout the year, without a distinct peak.
\end{abstract}

Key words: Pre-copula, pairing, ovigerous females, life history.

\section{INTRODUCTION}

Two reproductive strategies are relevant for gammarid amphipods: the male's active search for a mate and the pre-copula behavior. During pre-copula, days before the females' molt, the males grab the females using their gnathopods, and the couple remains swimming together until the copula itself occurs (Strong, 1973). This particular behavior happens due to the fact that females only copulate when they are "soft", i.e., soon after they molted and the new exoskeleton is not sclerotized yet (Strong, 1973; Conlan, 1991).

Environmental conditions, such as food availability, are extremely important for the reproductive success of a population. In adverse conditions, an increase in the egg and juvenile sizes trades-off with a decrease in the number of eggs in some crustaceans (Clutton-Brock, 1991). The female size is also an important factor in fecundity, since larger females produce more eggs (Steele and Steele, 1991).

Hyalella Smith, 1874 is a genus of freshwater amphipods found only in the American continent. Hyalella carstica Bastos-Pereira and Bueno, 2012 is a newly described species, and it is present in the Minas Gerais state of Brazil, a region with peculiar characteristics due to an intense environmental degradation caused by mining (Bastos-Pereira and 
Bueno, 2012). Here we studied the reproductive ecology of $H$. carstica in a natural environment, addressing its fecundity, pairing patterns and reproductive period throughout the year.

\section{Material and Methods}

This study was conducted in southeastern Brazil, in the West of the Minas Gerais state, in an area located between Arcos and Pains municipalities $\left(20^{\circ} 20^{\prime} 01.5^{\prime} \mathrm{S} 45^{\circ} 36^{\prime} 40.7^{\prime \prime} \mathrm{W}\right)$. Along with Doresópolis, the geology and speleology of these two municipalities were well studied due to interest in their unique rock formations (Menegasse et al., 2002). The subtropical region where the municipalities are located has wet summers, dry winters, and an annual mean precipitation of 1,344 $\mathrm{mm}$ (Menegasse et al., 2002). Since the dry season often leads to the complete disappearance of some streams in the region, the landscape is subject to changes in the hydric dynamics of the water bodies.

The stream where the samplings were taken belongs to the São Francisco river watershed. This area is considered an important karst aquifer due to its potential of hydric reloading (Menegasse et al., 2002). During the dry season the stream water flow is interrupted at a little dam set in its course (personal observation). The drought period lasts from May to September, and the regularization of the flow usually occurs in October (Menegasse et al., 2002).

Monthly, from April, 2010 to April, 2011, Hyalella carstica were sampled for 20 minutes using a hand net with $15 \mathrm{~cm}$ of diameter and $250 \mu \mathrm{m}$ mesh size, in a backwater area of the stream where the flow was slower. Ovigerous females and couples in pre-copula were individualized in microtubes, so in case they were separated, the respective pairs would not get lost.

After sampling the crustaceans, and in the same place, environmental parameters (conductivity, dissolved oxygen (DO), temperature and $\mathrm{pH}$ ) were measured using a digital portable meter placed below the water surface.

The ratio of paired and unpaired males and females was evaluated, and the developmental stage of the eggs was recorded. To categorize the eggs, the five stages described by Dick et al. (1998) for
Amphipoda were used: Stage 1) dark, homogeneous eggs; Stage 2) recently formed embryos are visible, but without eyes; Stage 3) embryos are more developed, with visible eyes; Stage 4) embryos fill the egg and have an orange color; Stage 5) fully developed and hatched juveniles that have not abandoned the marsupium yet.

\section{Data analysis}

The individual's head length (HL) was measured with a stereomicroscope containing a millimetric lens $(0.01 \mathrm{~mm})$. We used the Pearson correlation to determine if there was an individual size preference among pairs, comparing the HL of each individual with their respective pair. The relationship between the females HL and the number of eggs was determined using a simple linear regression. Statistical analyses were performed in Bioestat 5.0 and SigmaStat 3.1, using a 5\% level of significance.

\section{Results}

\section{Pairing}

In this Hyalella carstica population, couples in precopula were found throughout all the year, except in April, 2010. In the months before the dry season (September-November) the number of couples was high and gradually decreased until the stream had disappeared completely. After the superficial course of the stream returned, the abundance of couples increased again every month. Considering the total number of adults in each month, the highest proportion of adults in pre-copula, compared to the unpaired adults, was observed in August, 2010, and February and April, 2011.

The relationship between the HL of paired males and females was not significant $(\mathrm{r}=0.26 ; \mathrm{p}=0.10)$, what suggests that pairing in $H$. carstica is not related to the size of individuals.

The paired males/unpaired males (PM/M) ratio was low in all months, and always lower than 1 , which indicates that in any month the number of males in pre-copula was lower than the number of unpaired males (Fig. 1A). However, the months with highest proportion of paired males were August, 2010, just before drought, and February 2011, after the return of the rain for the region. Regarding females, the paired females/unpaired 
females $(\mathrm{PF} / \mathrm{F})$ ratio was also low. Only in February, 2011 there was a higher number of paired females when compared to unpaired ones (Fig. 1B).

\section{Fecundity}

Ovigerous females were found in all months, except in March, 2011 and during the dry season (September-November). A total of 207 ovigerous females were found, with eggs in different developmental stages and with juveniles. Ovigerous females were found in higher proportion when compared to non-ovigerous females after the dry season, with the exception of March (Tab. 1). The only month where the ratio was lower than 1 was May, 2010. This means that, during most of the study, most $H$. carstica females in this population were ovigerous.

Regarding the fecundity, a mean of $12.6 \pm$ 7.2 eggs per female was found. The months right after the dry season had a higher mean of eggs per female (Tab.1), with a significant difference among the sampling months $(\mathrm{p}<0.001)$. A high number of females carrying eggs in the first stage of development was observed (Fig. 2). Eggs in different stages were found throughout the year.

The HL of females was directly related to the number of eggs they were carrying $\left(\mathrm{R}^{2}=0.28\right.$; $\mathrm{p}<0.001$ ), indicating that females with larger HL will carry more eggs in the marsupium (Fig. 3).

\section{Environmental data}

The mean water temperature over the months was

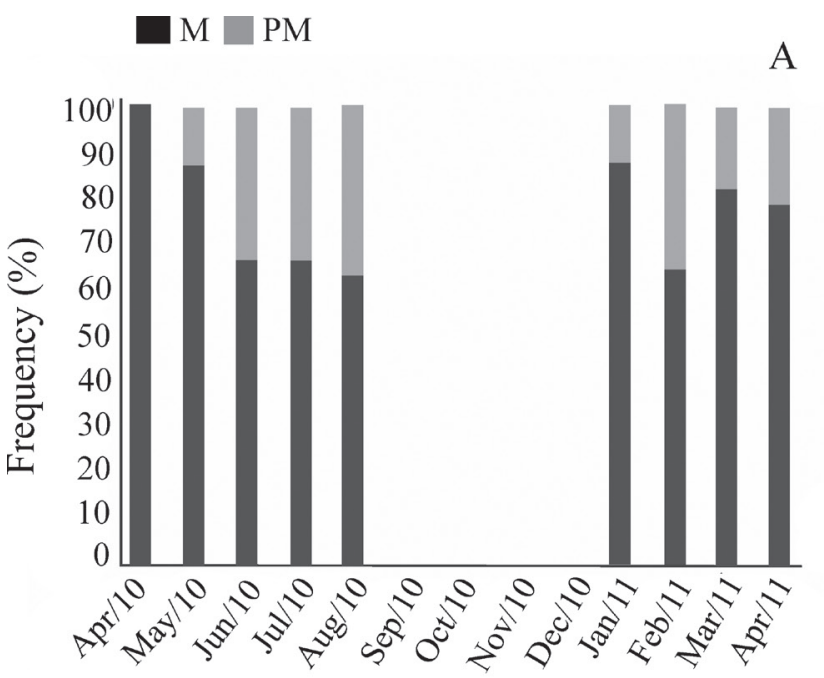

Sampling months
A

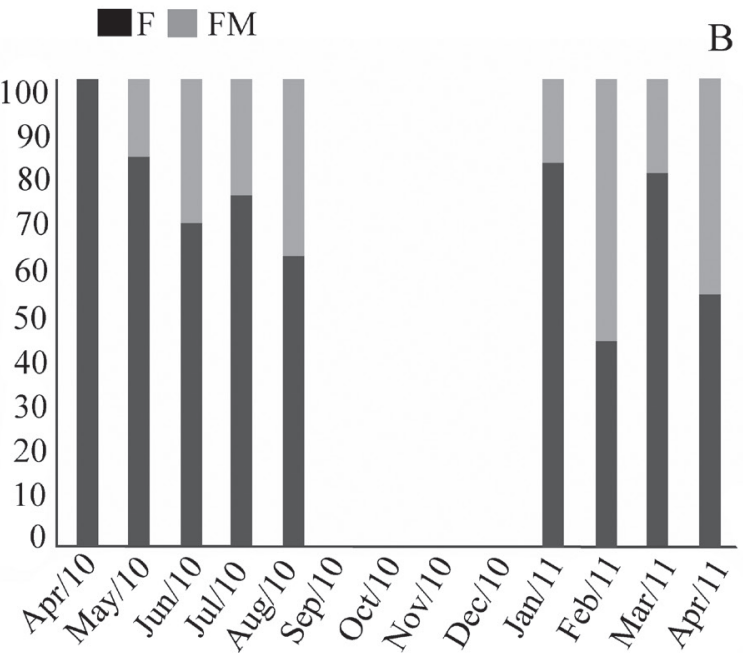

Sampling months

Figure 1. Proportion between paired and unpaired males (A) and females (B) in a population of Hyalella carstica in a stream in Arcos, Minas Gerais, Brazil, from April/2010 to April/2011. PM = paired males; $M=$ unpaired males; $P F=$ paired females; $F=$ unpaired females.

Table 1. Ratio between ovigerous females in relation to the total of females, mean number of eggs per female and couples in pre-copula found in a population of Hyalella carstica in in a stream in Arcos, Minas Gerais, Brazil, from April/2010 to April/2011. OF = ovigerous females; $\mathrm{F}=$ females; $\mathrm{SD}=$ standard deviation; $\mathrm{CP}=$ couples in pre-copula.

\begin{tabular}{cccc}
\hline Collection months & Ratio OF/F & Eggs/q (mean \pm SD) & Number of CP \\
\hline Apr/10 & 1.38 & $11.2 \pm 3.7$ & - \\
May/10 & 0.47 & $8.7 \pm 3.1$ & 18 \\
Jun/10 & 1.1 & $8.8 \pm 4.9$ & - \\
Jul/10 & 1.2 & $6.4 \pm 2.7$ & - \\
Aug/10 & 1.0 & $4.3 \pm 2.1$ & - \\
Sep/10 & - & - & - \\
Oct/10 & - & - & - \\
Nov/10 & - & - & - \\
Dec/10 & - & $14.1 \pm 5.8$ & 2 \\
Jan/11 & 2.0 & $20.1 \pm 7.8$ & 5 \\
Feb/11 & 3.5 & - & 6 \\
Mar/11 & - & $15.4 \pm 5.6$ & 11 \\
Apr/11 & 1.4 & & \\
\hline
\end{tabular}


$22.68^{\circ} \mathrm{C} \pm 3.17$, and it was higher after the drought. The mean dissolved oxygen was $6.63 \mathrm{mg} . \mathrm{L}^{-1} \pm 1.80$, and the mean conductivity was $48.67 \mu \mathrm{S} . \mathrm{cm}^{-2} \pm$ 11.75. The $\mathrm{pH}$ varied slightly around neutrality, averaging $7.43 \pm 0.29$ (Tab. 2). During the dry season, it was not possible to measure these variables at the study site, since the sampling site had no water.

\section{DisCUSSION}

The proportion of couples in the population of Hyalella carstica was slightly low, when compared to unpaired adults, even though couples were observed in all months. The same was observed for other species of Hyalella: Hyalella castroi Gonzalez, BondBuckup and Araujo, 2006 had 12.8\% of males and $10.7 \%$ of females in pre-copula, and Hyalella pleoacuta Gonzalez, Bond-Buckup and Araujo, 2006 had $16.5 \%$ of males and $14.4 \%$ of females

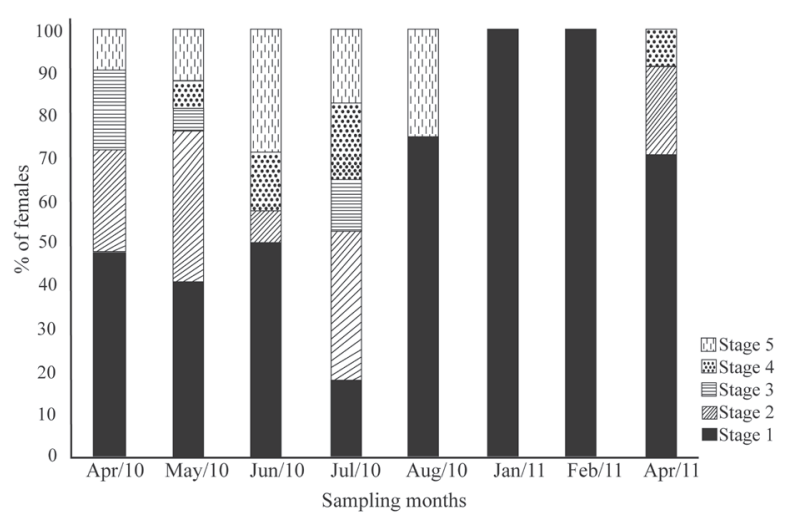

Figure 2. Percentage of females carrying eggs of each stage in a population of Hyalella carstica in a stream in Arcos, Minas Gerais, Brazil, from April/2010 to April/2011.
(Castiglioni and Bond-Buckup, 2008b).

The low occurrence of couples in this $H$. carstica population can be related to the fact that the individuals stay in pre-copula for a short time, approximately 3 days (personal observation), since this behavior can make individuals more vulnerable to predation (Strong, 1973; Wellborn, 1995). Furthermore, when in couples, individuals that inhabit locations where predators usually prey on larger organisms have a higher mortality rate. Besides, the paired individuals swim slower than unpaired ones (Cothran, 2004). Moreover, the sampling procedures may have led to the separation of individuals.

An important factor that must be considered is the drought period to which the $H$. carstica population was exposed. During the months when the water ceased to flow, and the organisms survived in ponds used as refuges, the conditions

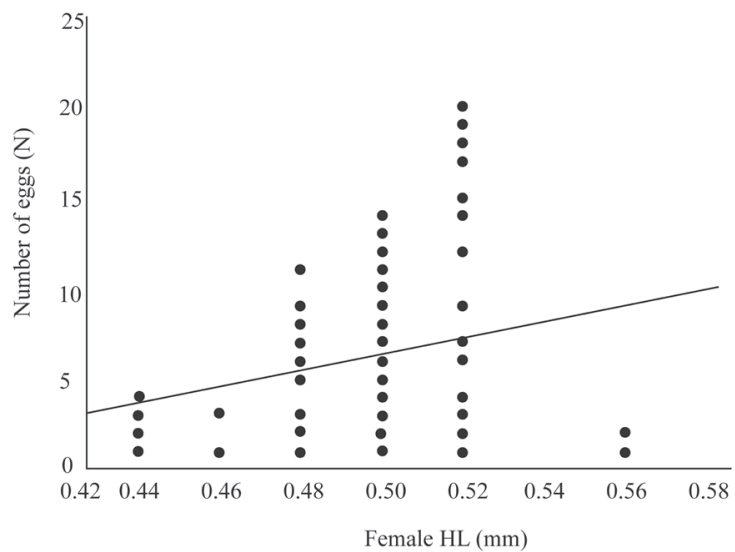

Figure 3. Linear regression between the females head length (HL) and the number of eggs contained in their marsupium for a population of Hyalella carstica in a stream in Arcos, Minas Gerais, Brazil, from April/2010 to April/2011.

Table 2. Physico-chemical parameters of the stream in which Hyalella carstica in a stream in Arcos, Minas Gerais, Brazil, from April/2010 to April/2011. Temp. $=$ Temperature $\left({ }^{\circ} \mathrm{C}\right) ; \mathrm{DO}=$ dissolved oxygen $\left(\mathrm{mg} . \mathrm{L}^{-1}\right) ;$ Cond. $=$ Electrical conductivity $\left(\mu \mathrm{S} . \mathrm{cm}^{-2}\right) ;{ }^{*} \mathrm{dry}$ period, unavailable data.

\begin{tabular}{ccccc}
\hline Collection months & Temp. & pH & DO & Cond. \\
\hline Apr/10 & 24.1 & 7.3 & 6.6 & 56 \\
May/10 & 19.8 & 7.5 & 5.9 & 63 \\
Jun/10 & 19.1 & 7.5 & 5.5 & 64 \\
Jul/10 & 15.8 & 7.4 & 4.7 & 75 \\
Aug/10 & 20.1 & 7.8 & 8.2 & 56 \\
Sep/10 & $*$ & $*$ & $*$ & $*$ \\
Oct/10 & $*$ & $*$ & $*$ & $*$ \\
Nov/10 & $*$ & 6.69 & 5.37 & 48 \\
Dec/10 & 23.6 & 7.4 & 8 & 45.1 \\
Jan/11 & 25.9 & 7.4 & 10.8 & 43.7 \\
Feb/11 & 25 & 7.4 & 6.38 & 38.1 \\
Mar/11 & 24 & 7.68 & & \\
Apr/11 & 21.6 & & & $*$ \\
\end{tabular}


for reproduction might not be optimal (Lake, 2003). Ovigerous females were observed upstream in the river, in permanently wet places. Once the population was reestablished, the amphipods resumed reproducing regularly at the sampling site. Temperature is the most important factor controlling the reproductive stage (March, 1977), and in this study, after dry period temperature (Tab. 2) was ideal for the reproduction of $H$. carstica.

Another factor that must be taken into consideration is the relative body size difference between genders. Some studies with different species of amphipods showed that larger males prefer to mate with larger females (Dick and Elwood, 1993; Wellborn, 1995, Castiglioni and Bond-Buckup, 2008b; Franceschi et al., 2010; Hume et al., 2005), but in other cases this did not occur (Wellborn, 1995; Wellborn and Bartholf, 2005). The lack of relationship can be due to the fact that there was no significant variation between the size of paired males, or to the fact that females of all sizes were found in pairs (Wellborn, 1995). The females of the $H$. azteca species complex seem to control when the pre-copula begins, as well as how long this behavior lasts (Wellborn and Bartholf, 2005), since females are only receptive to males a few days before molting (Cothran, 2004).

The reproduction of $H$. carstica population was continuous throughout most of the year. Many authors, studying different species of amphipods, also observed ovigerous females along the entire sampling period (Strong, 1972; Casset et al., 2001; Guerao, 2003; Kevrekidis, 2005; Castiglioni and Bond-Buckup, 2008a). The proportion of females with eggs in marsupium can vary in a significant way, even though they were found in almost all months, presenting abundance peaks when the conditions were more favorable (Cooper, 1965). Ovigerous females of $H$. carstica were observed during the dry months in the upstream part of the river that does not dry, indicating that reproduction continues even during the drought. The same was observed in two other studies on different populations of $H$. azteca (Edwards and Cowell, 1992; Pickard and Benke, 1996).

The prevalence of ovigerous females, in relation to those without eggs, was observed in other studies on freshwater amphipods (Kevrekidis, 2005; Kestrup and Ricciardi, 2010). In addition, this does not happen only in the freshwater, as shown by Maranhão et al. (2001) in a population of Echinogammarus marinus (Leach, 1815). For this marine amphipod, the percentage of ovigerous females was higher than that of non-ovigerous during the whole year.

Females of freshwater amphipods usually have larger eggs than females of marine amphipods (Steele and Steele, 1991). However, with respect to the number of eggs, Hyalella has a low number when compared to other gammarids, and their juveniles are larger when they hatch (Strong, 1972; Wellborn et al., 2005). In the present study, the dry season was an important factor for the egg production, since in the months before drought the mean number of eggs was lower. However, after that period, females produced a higher number of eggs, maybe to recover the population size after the re-colonization of their habitat.

In this study, the developmental stage of the eggs of each female was also recorded and, as observed in H. azteca by Strong (1973), the reproduction was not synchronized. This means that most stages are found throughout the year, even though all eggs within a single female are at the same developmental stage. This happens not only in Hyalella, but also in other amphipods, including marine species (Maranhão et al., 2001). The high number of $H$. carstica females with eggs in the first stage may be related to the fact that some eggs may be discarded, since some of them can be unfeasible and/or not fertilized yet (Cothran et al., 2010). Besides, this stage lasts the longest. Females with eggs in the first stage were also the majority in a population of the amphipod Crangonyx pseudogracilis Bousfield, 1958: $65 \%$ of females had eggs in the first three stages. Usually, the number of eggs per female decreases from the first to the last stage (Dick et al., 1998), due to embryo mortality.

As in many other crustaceans and in $H$. carstica, female body size is a good indicator of fecundity. Many authors already observed a positive correlation between HL and the number of eggs in the marsupium, thus larger females carry more eggs (Cooper, 1965; Strong, 1972; Steele and 
Steele, 1991; Wellborn, 1995; Maranhão et al., 2001; Guerao, 2003; Wellborn and Bartholf, 2005; Castiglioni and Bond-Buckup, 2007).

The reproduction of $H$. carstica was continuous along the year: couples in pre-copula and ovigerous females were found every month. Many authors stated that this characteristic is more common in tropical populations, where the food availability and the environmental factors are steadier and favor a longer reproduction period. Another aspect that corroborates the continuous recruitment hypothesis is the fact that, in a given moment, all egg stages were found in the population, but there was no synchronic hatching of juveniles. In this way, there are always new individuals entering the population. The positive relationship observed between the ovigerous females' HL and the number of eggs in the marsupium indicates that larger females contribute with a greater progeny to the population. Understanding the reproductive aspects of a population is important, since they allow us to infer about the capacity of such population to maintain itself through time in a given environment, thus helping the discussion of conservational policies.

\section{ACKNOWLEDGEMENTS}

The authors would like to thank the Brazilian CNPq for grants, and all the members of the Carcinology Laboratory of UFLA.

\section{REFERENCES}

Bastos-Pereira, R. and Bueno, A.A.P. 2012. New species and new report of Hyalella S.I. Smith 1874 (Crustacea: Amphipoda: Dogielinotidae) from Minas Gerais state, Southeastern Brazil. Zootaxa, 3350: 58-68.

Bousfield, E.L. 1958. Littoral marine arthropods and mollusks collected in western Nova Scotia, 1956. Proceedings of the Nova Scotian Institute of Science, 24: 303-325.

Casset, M.A.; Momo, F.R. and Giorgi, A.D.N. 2001. Dinámica poblacional de dos especies de anfípodos y su relación con la vegetación acuática en un microambiente de la cuenca del río Luján, Argentina. Ecologia Austral, 11(1): 79-85.

Castiglioni, D.S. and Bond-Buckup, G. 2007. Reproductive strategies of two sympatric species of Hyalella Smith, 1874 (Amphipoda, Dogielinotidae) in laboratory conditions. Journal of Natural History, 41(25/28): 1571-1584.

Castiglioni, D.S. and Bond-Buckup, G. 2008a. Ecological traits of two sympatric species of Hyalella Smith, 1874 (Crustacea, Amphipoda, Dogielinotidae) from southern Brazil. Acta Oecologica, 33(1): 36-48.
Castiglioni, D.S. and Bond-Buckup, G. 2008b. Pairing and reproductive success in two sympatric species of Hyalella (Crustacea, Amphipoda, Dogielinotidae) from southern Brazil. Acta Oecologica, 33(1): 49-55.

Clutton-Brock, T.H. 1991. The evolution of parental care. Princeton, Princeton University, 352p.

Conlan, K.E. 1991. Precopulatory mating behavior and sexual dimorphism in the amphipod Crustacea. Hydrobiologia, 223(2): 255-282.

Cooper, W.E. 1965. Dynamics and production of a natural population of a fresh-water amphipod, Hyalella azteca. Ecological Monographs, 35(4): 377-394.

Cothran, R.D. 2004. Precopulatory mate guarding affects predation risk in two freshwater amphipod species. Animal Behaviour, 68(5): 1133-1138.

Cothran, R.D.; Kuzmic, A.; Wellborn, G.A. and Relyea, R.A. 2010. Phenotypic manipulation provides insights into the function of a sexually selected trait in a freshwater crustacean species complex. Animal Behaviour, 80(3): 543-549.

Dick, J.T.A. and Elwood, R.W. 1993. The mating system of Gammarus pulex: a negligible role for micro-habitat segregation. Animal Behaviour, 45(1): 188-190.

Dick, J.T.A.; Faloon, S.E. and Elwood, R.W. 1998. Active brood care in an amphipod: influences of embryonic development, temperature and oxygen. Animal Behaviour, 56(3): 663-672.

Edwards, T.D. and Cowell, B.C. 1992. Population dynamics and secondary production of Hyalella azteca (Amphipoda) in Typha stands of a subtropical Florida lake. Journal of the North merican Benthological Society, 11(1): 69-79.

Franceschi, N.; Lemaître, J.F.; Cézilly, F. and Bollache, L. 2010. Size-assortative pairing in Gammarus pulex (Crustacea: Amphipoda): a test of the prudent choice hypothesis. Animal Behaviour, 79(4): 911-916.

Gonzalez, E.R.; Bond-Buckup, G. and Araujo, P.B. 2006. Two new species of Hyalella from southern Brazil (Amphipoda: Hyalellidae) with a taxonomic key. Journal of Crustacean Biology, 26(3): 355-365.

Guerao, G. 2003. Some observations on the life history of the freshwater amphipod Echinogammarus longisetosus Pinkster, 1973 (Gammaridae) from Catalonia (Spain, N Iberian peninsula). Animal Biodiversity and Conservation, 26(1): 31-39.

Hume, K.D.; Elwood, R.W.; Dick, J.T.A. and Morrison, J. 2005. Sexual dimorphism in amphipods: the role of male posterior gnathopods revealed in Gammarus pulex. Behavioral Ecology and Sociobiology, 58(3): 264-269.

Kestrup, A. and Ricciardi, A. 2010. Influence of conductivity on life history traits of exotic and native amphipods in the St. Lawrence River. Fundamental and Applied Limnology, 176(3): 249-262.

Kevrekidis, T. 2005. Life history, aspects of reproductive biology and production of Corophium orientale (Crustacea: Amphipoda) in Monolimni lagoon (Evros Delta, North Aegean Sea). Hydrobiologia, 537(1): 53-70.

Lake, P.S. 2003. Ecological effects of perturbation by drought in flowing waters. Freshwater Biology, 48(7): 1161-1172. 
Leach, W.E. 1815. A tabular view of the external characters of four classes of animals, etc. I Crustacea. Transactions of the Linnean Society of London, XI: 306-400.

Maranháo, P.; Bengala, N.; Pardal, M. and Marques, J.C. 2001. The influence of environmental factors on the population dynamics, reproductive biology and productivity of Echinogammarus marinus Leach (Amphipoda, Gammaridae) in the Mondego estuary, Portugal. Acta Oecologica, 22(2): 139-152.

March, B.G.E. 1977. The effects of photoperiod and temperature on the induction and termination of reproductive resting stage in the freshwater amphipod Hyalella azteca (Saussure). Canadian Journal of Zoology, 55(10): 1595-1600.

Menegasse, L.N.; Gonçalves, J.M. and Fantinel, L. 2002. Disponibilidades hídricas na província cárstica de ArcosPains-Doresópolis, Alto São Francisco, Minas Gerais, Brasil. Revista de Águas Subterrâneas, Rio Claro, 16(1): 2-19.

Pickard, D.P. and Benke, A.C. 1996. Production dynamics of Hyalella azteca (Amphipoda) among different habitats in a small wetland in the Southeastern USA. Journal of the North American Benthological Society, 15 (4): 537-550.

Smith, S.I. 1874. The Crustacea of the freshwaters of the United States - synopsis of the higher freshwater Crustacea of the Northern United States. Report of the Commissioner of Fish and Fisheries, 2: 637-665.

Steele, D.H. and Steele, V.J. 1991. Morphological and environmental restraints on egg production in amphipods. p. 157-170. In: F.R. Schram (ed), Crustacean Egg Production. Crustacean Issues, Vol. 1. Rotterdam, Balkema.

Strong, D.R. 1972. Life history variation among populations of an Amphipod (Hyalella azteca). Ecology, 53(6): 11031111.

Strong, D.R. 1973. Amphipod amplexus: the significance of ecotypic variation. Ecology, 54(6): 1383-1388.

Wellborn, G.A. 1995. Determinants of reproductive success in freshwater amphipod species that experience different mortality regimes. Animal Behaviour, 50(2): 353-363.

Wellborn, G.A. and Bartholf, S.E. 2005. Ecological context and the importance of body and gnathopod size for pairing success in two amphipod ecomorphs. Behavioural Ecology, 143(2): 308-316.

Wellborn, G.A.; Cothran, R.D. and Bartholf, S.E. 2005. Life history and allozyme diversification in regional ecomorphs of the Hyalella azteca (Crustacea: Amphipoda) species complex. Biological Journal of the Linnean Society, 84(1): $161-175$. 
